\title{
Escritores e tradutores: apresentação
}

Writers and Translators: Foreword

Professor de Língua e Literatura Alemã, Língua e Literatura Inglesa e docente permanente do
Programa de Pós-Graduação em Letras da Pontifícia Universidade Católica do Rio Grande do Sul. É editor de Letrônica e um dos responsáveis pela organização do presente número. E-mail: perth@pucrs.br

pros em Estudios Culturales e Hispánicos, professora titular da Facultad de Ciencias de Colombia. Co-organizadora do presente número de Letrônica.

(i) https:///orcid.org/0000-0002-8948-3402 E-mail: mmdvalle@unisalle.ducom
Pedro Theobald ${ }^{1}$

Pontifícia Universidade Católica do Rio Grande do Sul, Escola de Humanidades, Porto Alegre, RS, Brasil. Mónica María Del Valle Idárraga² Universidad de La Salle, Facultad de Ciencias de la Educación, Bogotá, Colombia.

presente edição da revista Letrônica tem como tema as relações entre o escrever e o traduzir. Conforme bem sabem Aos que se dedicam a essas atividades, a prática da escrita é imprescindível para se exercer a profissão de tradutor, se abstrairmos o reduzido número daqueles profissionais que se dedicam exclusivamente à interpretação, que consiste na forma oral da tradução. Por outro lado, embora ser tradutor não constitua requisito para ser escritor, os profissionais da escrita em todas as áreas têm evidenciado cada vez mais que a leitura e a tradução de textos em línguas estrangeiras são essenciais para o enriquecimento de seu mundo de ideias, quando não para o exercício proficiente e a renovação formal de seu mister. Esse último aspecto diz respeito sobretudo à área literária, mais especialmente à poesia.

Exemplos de escritores tradutores são inúmeros, em certos casos não se sabendo exatamente qual das atividades tem precedência. Restringindo-nos aos séculos recentes e a apenas algumas culturas, lembremos aqui os nomes de Jorge Luis Borges, Ezra Pound, Vladimir Nabokov, Rachel de Queiroz, Carlos Drummond de Andrade, Manuel Bandeira, Guilherme de Almeida, Cecília Meireles, José Paulo Paes, Augusto de Campos, Haroldo de Campos, Décio Pignatari, Lya Luft, Daniel Galera, e Hamilton Bettega Barbosa. Na realidade, o número de exemplos é tão grande que em praticamente cada língua e em cada época existe um nome emblemático. Alguns desses nomes já aparecem em obras pioneiras sobre o assunto no Brasil, como A tradução vivida, de Paulo Rónai (1976), e Tradução: ofício e arte, de Erwin Theodor (1976). Sobre outros já existem estudos individuais, como acontece com Rachel de Queiroz (SOUSA et al., 2015). Na língua portuguesa, alguns dos citados são obrigatórios quando se menciona o assunto. É o caso dos irmãos Campos, que transcenderam os limites de sua própria língua e se tornaram referência internacional. 
O tema escrever e traduzir insere-se na área dos Estudos de Tradução. A abrangência da área possibilita a investigação de inúmeros temas específicos, dentre eles história da tradução, natureza da tradução, tradução literária, autoria, influência, contaminação, (in)visibilidade do tradutor, recepção da tradução, mercado editorial. O desenvolvimento desses estudos em detalhados projetos de pesquisa, nas universidades de todo o mundo, resultou em um corpus teórico que dá conta das numerosas nuances do tema aqui proposto.

Júlio Cortázar, literato formidável, elogiava a tradução como a maneira mais íntima e profunda de ler. Talvez tivesse razão. Em todo caso, essa afirmação assinala uma relação especial dos escritores com os textos em outras línguas, dos escritores com os tradutores ou consigo mesmos enquanto tradutores, ou, no mínimo, mostra um caminho pelo qual os escritores se nutrem das obras que leem em outras línguas e, muito mais, das obras que traduzem, independentemente de serem poéticas ou em prosa. Decorre daí que os limites entre a criação e a tradução se tornem porosos, nesses casos. Digamos que essa é outra faceta do controvertido debate que busca resguardar uma suposta originalidade das obras, em que a tradução fica submissa, dependente delas. Discussões sobre empréstimos, criação, transcriação, sobre o quanto o tradutor pode intervir na obra, aparecem e reaparecem continuamente, e são colocadas em relevo nas afirmações de escritores que traduzem a si mesmos, como Rosario Ferré (SPOTURNO, 2018), ou de autores que lutam obsessivamente através do tempo, em distintas tentativas, para dar conta de uma obra que amam, como no caso de Nabokov e de suas versões da obra de Pushkin (THIRLWELL, 2014). No fundo, a pergunta à qual nos convidam todos esses debates é a seguinte: já que um autor pode ser tradutor, sem que se julgue que está entrando em territórios proibidos, sem que se dispute sequer sua capacidade para o trabalho, pode em contrapartida considerar-se o tradutor como autor?

Ao lermos os artigos recebidos para esta edição, encontramos possíveis respostas a essa e outras perguntas. Em nível formal e institucional, percebemos não só que a internacionalização da bibliografia e a difusão dos Estudos de Tradução constituem fatos incontestes, mas também que a produção na área alcança os diversos níveis da Universidade, da graduação ao pós-doutorado. A edição apresenta treze artigos, procedentes de universidades brasileiras, em sua maioria, e uma resenha, que atestam esse âmbito, características de origem e localização da pesquisa.

O primeiro deles é "Entre a tradução e a escrita: reflexões sobre a domesticação, a visibilidade, a ética e a construção autoral do tradutor", de Bianca de Lima Reys e Valéria Brisolara. "Até que ponto o autor pode interferir na escrita do autor do original?" perguntam as autoras. O artigo trata dessa e das outras questões anunciadas no título de maneira teórica e as ilustra com exemplos da tradução própria do conto "The yellow wallpaper", de Charlotte Perkins Gilman.

O poeta norte-irlandês Paul Muldoon desenvolveu, ao longo de sua vida, um conceito pessoal “do que é e do que pode ser tradução". Suas ideias a respeito do assunto, bem como suas obras, entre as quais se incluem inúmeras traduções, são 
apresentadas e examinadas por Guilherme Bernardes no artigo "Paul Muldoon: traduções”, que, como o anterior, se destaca pelo embasamento teórico. $\mathrm{O}$ autor do artigo também propõe e discute quatro traduções próprias de poemas de Muldoon.

Questões relacionadas à tradução e à criação como atos simultâneos, bem como à contaminação do texto traduzido, são discutidas no artigo "A traduzir e criar: um exemplo de tradução por Rui Pires Cabral". Trata-se do poema "Landscape", da norte-americana Louise Glück, em tradução do poeta português Rui Pires Cabral, de que se apresentam e examinam várias versões.

"Ficções da tradução, traduções da ficção: o caso Ricardo Piglia" é o título de um artigo de Iuri Almeida Müller em que são estudadas as relações desse autor argentino com a tradução. Piglia, que traduziu poucas obras, no entanto se manifestou em diversas ocasiões sobre a tradução de forma crítica e ensaística, examinando o papel da tradução e do conhecimento das línguas estrangeiras na cultura argentina e em um de seus autores preferidos, Roberto Arlt.

O artigo "Traducción y escritura poética: dos facetas desconocidas del lingüista raizal Oakley Forbes", de Andrés Arboleda Toro, trata de temas como autotradução, tradução colaborativa e multilinguismo de escritura. Os temas são discutidos com base nas relações literárias multifacetadas entre os poetas caribenhos-colombianos contemporâneos Juan Ramírez Dawkins (1940-) e Oakley Forbes (1947-2016). O último, um linguista e poeta multilíngue (falava e escrevia em inglês, creole e espanhol), traduziu a obra do primeiro, mas também produziu uma obra própria que suscita importantes questões a respeito de autoria, contaminação e temas conexos.

Um autor importante que traduz outro também figura em "O autor que traduz: Chateaubriand e Paraíso perdido de John Milton”, por Cristian Cláudio Quinteiro Macedo. A tradução de René de Chateaubriand, realizada em 1836, é acompanhada de um paratexto relevante para a historiografia da tradução. Seguindo uma posição defendida por alguns até hoje, o tradutor preconizava a tradução "mot-à-mot", ou seja, literal, e chega a propor-se como modelo de tradutor. Opõe-se, dessa forma, a outra linha de tradução, já detectada na Renascença inglesa e que vigorou na França por vários séculos, conhecida por "as belas infiéis" (OUSTINOFF, p. 36).

Hilaire Belloc (1870-1953), autor franco-britânico, não se notabilizou por traduções, mas por uma obra - On translation (1931) - a respeito do tema. Ela nos é apresentada em "Tradução literária e as reflexões de Hilaire Belloc sobre a arte de traduzir", de Letícia Mendes Ferri. As posições de Belloc em relação a questões desafiadoras como (não) "traduzir o intraduzível" e (não) "traduzir versos em versos" certamente se chocam com o que um grande número de tradutores e teóricos defende hoje em dia.

"O enigma de 'Jabberwocky' na tradução de Augusto de Campos para o português brasileiro", artigo de Marinice Argenta e Sandra Sirangelo Maggio, trata de "Jaguadarte", título que o poema de Lewis Carroll em Através do espelho e o 
que Alice encontrou lá assumiu em sua recriação em português. A discussão de conceitos como nonsense e a observação acurada dos recursos linguísticos e literários de Carroll, e de sua recriação por Augusto de Campos, compõem alguns dos aspectos desse texto.

Tal como seu irmão Augusto, estudado no artigo anterior, Haroldo de Campos é constantemente associado a ideias, práticas e conceitos criativos e inovadores nos domínios da tradução. Isso fica evidente em "Pelas redes da tradução: um estudo do conceito de transcriação, de Haroldo de Campos, no poema 'Quisera no meu canto ser tão áspero', de Dante Alighieri" por Ana Carolina Lopes Costa. Além de discutir os conceitos e propósitos de Haroldo de Campos - citem-se a "tradução como criação e como operação crítica" e a "plagiotropia" ou "desvio criativo" -, o texto apresenta os resultados obtidos por ele na tradução do poema de Dante.

Carlos Drummond de Andrade, por vezes exaltado como grande tradutor de prosa, foi tradutor de Federico García Lorca no Brasil. Como tal, é estudado em "Drummond tradupoeta, ou Carlos de margem para margem”, de Daniel Soares Duarte. Segundo o autor do artigo, a leitura de Lorca constituiu "material poético pedagógico para Drummond”. A relação do poeta brasileiro com o poeta espanhol foi temática e formal e torna visível o fato de que a tradução funciona como dispositivo de conexão, não só entre autores, mas também entre sistemas literários.

Outro autor contemporâneo conhecido por sua produção literária é estudado por Andrea Cristiane Kahmman em "Sergio Faraco, inventor da literatura uruguaia". Com base no conceito de "sociologia da tradução", de Andrew Chesterman, a autora examina os variados aspectos que afetam o trabalho do tradutor, como condições de trabalho, remuneração, direitos autorais, associações profissionais, redes de tradução, agentes literários e assim por diante. Nessa forma de abordagem recente, substituem-se propostas comparativas tradicionais pela discussão da seleção das obras a traduzir e das escolhas lexicais do tradutor.

Rodrigo Lacerda, escritor, tradutor e editor, é apresentado em um artigo de Marcilene Moreira Donadoni. Trata-se de "Rodrigo Lacerda: estilos que se fundem entre a vida e os livros traduzidos". Baseado em levantamento abrangente, o estudo vê o escritor-tradutor em sua trajetória intelectual completa, que inclui seu desenvolvimento como leitor e seu trabalho de adaptador.

Encerra a seção de artigos a discussão de um tema de relevância e interesse que frequentemente acompanha o surgimento de obras literárias, e de traduções específicas - a questão do plágio. Paulo Roberto de Souza Ramos dedica ao assunto o extenso artigo "Uma fagulha de vida: discutindo tradução, adaptação e plágio a partir de Max e os felinos, de Moacyr Scliar e A sucessora, de Carolina Nabuco". Partindo de uma apresentação bem informada dos casos mencionados no título, Ramos discute os aspectos teóricos e as implicações legais do tema. 
No último texto desta edição da revista Letrônica apresentamos a resenha de uma obra não ficcional traduzida para o português. Trata-se de Como escrever bem, de William Zinsser. A resenha de Frederico Dollo Linardi examina o original dessa obra publicada sob o título On writing well e compara-o com a tradução brasileira de Bernardo Ajzenberg. São discutidos os desafios que a tradução desse manual apresenta ao tradutor, as soluções encontradas, bem como os motivos para as adaptações e omissões.

Agradecemos a participação de nossos colaboradores neste número e desejamos a todos uma leitura proveitosa.

\section{Referências}

OUSTINOFF, Michaël. Tradução: história, teorias e métodos. Trad. Marcos Marcionilo. São Paulo: Parábola, 2011.

RÓNAI, Paulo. A tradução vivida. Rio de Janeiro: Educom, 1976.

SOUSA, Germana Henriques Pereira de; RABELO, Lorena Melo; TIMO, Lorena Torres. Escritores brasileiros tradutores: o caso Rachel de Queiroz. In: SOUSA, Germana Henriques Pereira de (Org.). História da tradução: ensaios de teoria, crítica e tradução literária. Campinas: Pontes, 2015. p. 247-262. https://doi.org/10.2478/tran-2018-0003

SPOTURNO, Maria Laura. Self-retranslation as a rite of passage: Rosario Ferré’s English version of "La muñeca menor". Mutatis Mutandis, 11(2), 2018, p. 356-375. https://doi.org/10.17533/udea.mut.v11n2a04

THEODOR, Erwin. Tradução: ofício e arte. São Paulo: Cultrix; USP, 1976.

THIRLWELL, Adam. Homenaje a Vladimir Nabokov en tres idiomas. In: La novela múltiple. Barcelona: Anagrama, 2014. p. $375-404$.

Recebido em: 02/04/2019.

Aprovado em: 02/05/2019.

Publicado em: 20/6/201 